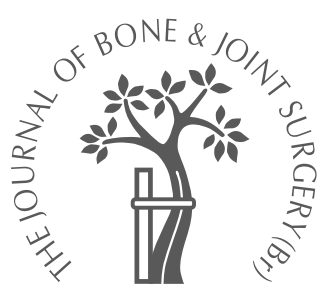
A. Clarke,
G. Dewnany,
L. Neumann,
W. A. Wallace

From Nottingham

Shoulder and Elbow

Unit, Nottingham

City Hospital,

England

\title{
Glenothoracic fusion
}

\author{
AN ADJUNCT TO RADICAL SCAPULECTOMY
}

\begin{abstract}
A. Clarke, MRCS, Clinical Research Fellow

Centre for Spinal Studies and Surgery, Queen's Medical Centre, Nottingham NG7 $2 \mathrm{UH}, \mathrm{UK}$.

G. Dewnany, FRCS (Trauma \& Orth), Specialist Registrar

Department of Trauma and Orthopaedic Surgery,

Northern General Hospital, Herries Road, Sheffield S5 7AU, UK.

L. Neumann, FRCS Ed, Consultant Orthopaedic Surgeon

W. A. Wallace, FRCS Ed, Professor of Trauma and Orthopaedic Surgery Nottingham Shoulder and Elbow Unit, Nottingham City Hospital, Hucknall Road, Nottingham NG5 1PB, UK.
\end{abstract}

Correspondence should be sent to Mr L. Neumann.

C2004 British Editorial Society of Bone and Joint Surgery doi:10.1302/0301-620X.86B4. $14367 \$ 2.00$

$J$ Bone Joint Surg [Br] 2004;86-B:531-5.

Received 27 March 2003

Accepted after revision

12 September 2003

We describe a surgical procedure used to achieve glenothoracic fusion after one-stage radical, near total scapulectomy for primary or secondary malignant lesions in six patients. The aim was complete excision of the lesion and preservation of the glenoid to provide a fulcrum for movement of the arm.

Post-operative assessment involved determination of the range of movement and the application of the Musculoskeletal Tumour Society score and the Constant score to evaluate function. The results showed that a functional range of movement was attainable despite such radical surgery, although there was a considerable reduction in power and ability to lift.

The scapula is essential for the function of the shoulder. It provides components for three of the four joints which comprise the shoulder complex and attachments for the muscles responsible for moving and stabilising both the glenohumeral and the scapulothoracic joints. It acts as a fulcrum about which the arm is moved.

Liston ${ }^{1}$ was the first to propose excision of the scapula and performed a partial removal for an 'osteoaneurysm'. Scapulectomy for a malignant tumour was described by Syme of Edinburgh in $1856 .^{2}$ His series of three patients included a postman who returned to work after his operation. Figure 1 shows the cosmetic and functional result obtained.

Syme's approach to the scapula was superseded by more radical operations such as Berger's interscapulothoracic amputation. ${ }^{3}$ However, Linberg ${ }^{4}$ highlighted the mutilation caused by Berger's operation and developed a limb-sparing procedure. This represented a move towards considering the functional outcome as well as excision of the tumour. Francis and Worcester ${ }^{5}$ and Badley and Lee $^{6}$ considered that preservation of the original structures, when possible, would lead to improved function. Our aim for glenothoracic fusion adheres to this philosophy, which is to excise the tumour and retain a fulcrum about which the arm can move. We present the medium-term functional results of six patients who have undergone such a fusion.

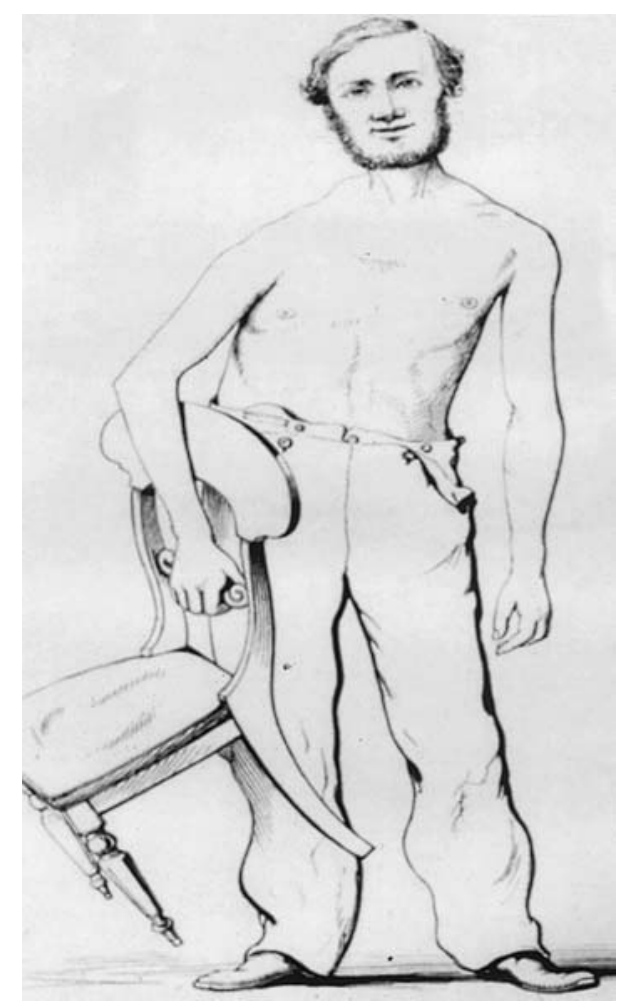

Fig. 1

A line drawing of Syme's patient copied from his monograph 'Excision of the scapula' in 1864

\section{Patients and Methods}

We have studied six patients who underwent a glenothoracic fusion between 1989 and 1999. Patients with both primary and secondary malignancies of the scapula were offered this procedure. Table I gives the clinical details. 
Table I. Clinical details of the six patients undergoing glenothoracic fusion

\begin{tabular}{llllllll}
\hline Case & Gender & $\begin{array}{l}\text { Age } \\
\text { (yrs) }\end{array}$ & Diagnosis & Side & Follow-up & Alive & Cause of death \\
\hline 1 & $\mathrm{M}$ & 35 & Chondrosarcoma & $\mathrm{L}$ & 12 yrs and well & $\mathrm{Y}$ & - \\
2 & $\mathrm{~F}$ & 64 & Chondrosarcoma & $\mathrm{R}$ & 2 yrs and well & $\mathrm{Y}$ & - \\
3 & $\mathrm{M}$ & 64 & Thyroid carcinoma & $\mathrm{R}$ & $2.5 \mathrm{yrs}$ & $\mathrm{N}$ & Metastases \\
4 & $\mathrm{M}$ & 71 & Prostatic carcinoma & $\mathrm{L}$ & $2 \mathrm{yrs}$ & $\mathrm{N}$ & Metastases \\
5 & $\mathrm{M}$ & 68 & Myxoid liposarcoma & $\mathrm{R}$ & 10 mths & $\mathrm{N}$ & $\begin{array}{l}\text { Myocardial } \\
\text { infarction }\end{array}$ \\
6 & $\mathrm{M}$ & 21 & Ewing's sarcoma & $\mathrm{R}$ & 6 mths & $\mathrm{N}$ & Metastases \\
\hline
\end{tabular}

The patients had a detailed clinical and radiological examination to ensure that the tumour was resectable. MRI and/or CT was used to obtain accurate anatomical information about the extent of the lesions and their exact anatomical relations. No functional assessments were recorded before surgery (Fig. 2).

Operative treatment. The patients were placed in the lateral position, with the affected scapula uppermost. The incision was dictated by the size and shape of the tumour and by the site of prior biopsy wounds. Osteotomy was performed through the neck of the scapula (Fig. 3) retaining as much

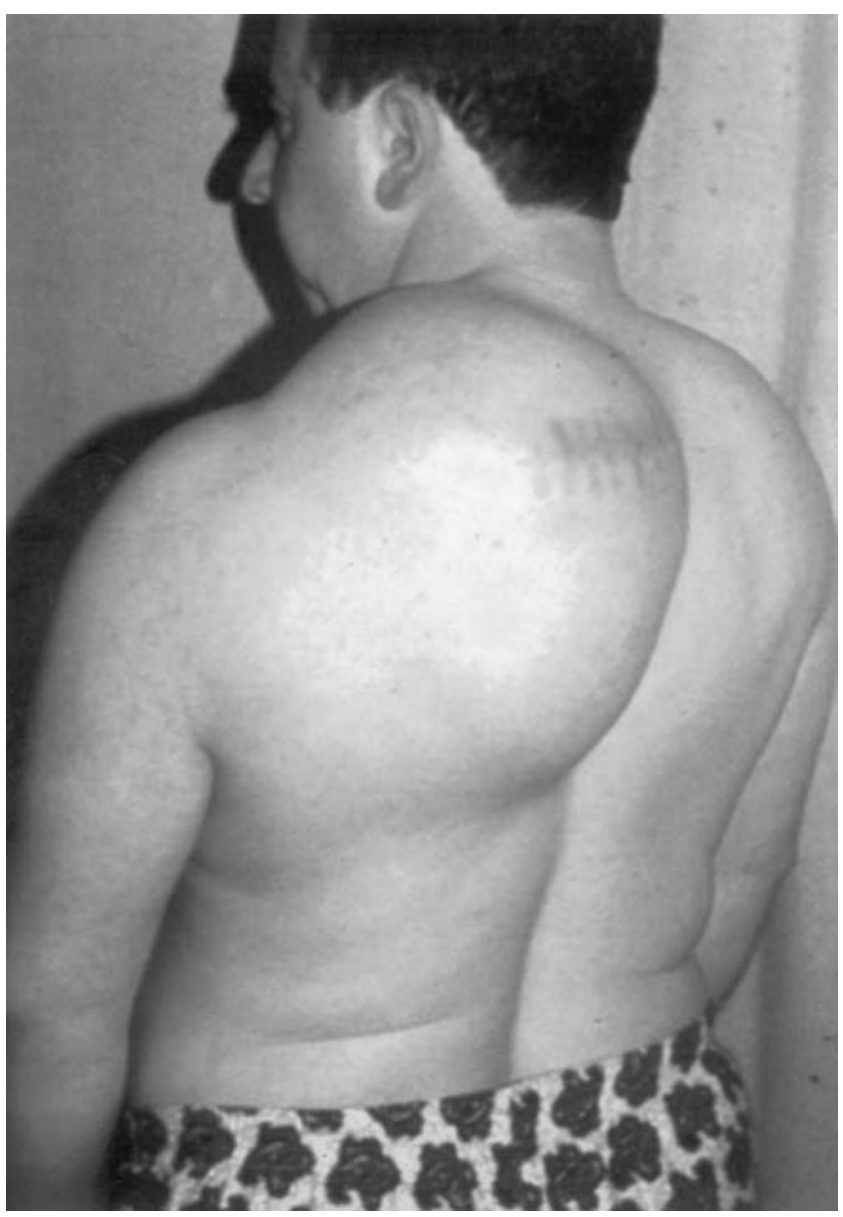

Fig. 2

Case 1. Pre-operative photograph after open biopsy. of the neck of the glenoid as possible to preserve the capsule of the glenohumeral joint and associated ligaments. The soft tissues, including the rotator cuff and adjacent nerves were sacrificed when necessary. When the tumour had been removed completely, the remaining tissue was re-examined to ensure that the joint was salvageable. Two holes, spaced to the size of the glenoid remnant were then drilled in a posteroanterior direction through the neck of the scapula. Two adjacent ribs, usually the second, third or fourth were cleared of periosteum and the scapular remnant was fixed to them using 18-gauge wire. Morsellised allograft was then packed around the thoracoglenoid synostosis to encourage bony union.

Review. The patients underwent careful assessment at each follow-up. We recorded the range of movement in flexion, abduction, internal and external rotation.

Functional assessment scores such as that of the Musculoskeletal Tumour Society ${ }^{7}$ (MSTS) and of Constant and Murley ${ }^{8}$ were used in three patients (cases 1 to 3).

\section{Results}

Measurements of the post-operative ranges of movement showed that the mean forward flexion was $66.7^{\circ}$ (45 to 90 ); the mean abduction $68.3^{\circ}$ (40 to 90 ); the mean internal rotation, $89.2^{\circ}$ (45 to 90 ) and the mean external rotation, $16.7^{\circ}(0$ to 50$)$. Table II gives the range of movement for all

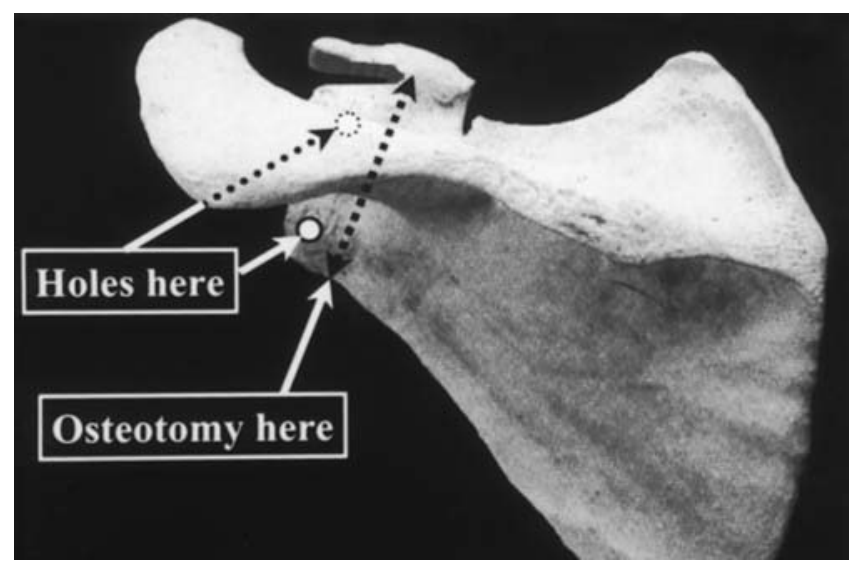

Fig. 3

Photograph showing details of the scapular osteotomy from the posterior aspect. 
Table II. The range of movement (degrees) at the glenohumeral joint at the last follow-up

\begin{tabular}{lllll}
\hline Case & Flexion & Abduction & $\begin{array}{l}\text { Internal } \\
\text { rotation }\end{array}$ & $\begin{array}{l}\text { External } \\
\text { rotation }\end{array}$ \\
\hline 1 & 90 & 90 & 90 & 20 \\
2 & 45 & 40 & 80 & 0 \\
3 & 75 & 80 & 90 & 10 \\
4 & 50 & 60 & 50 & 10 \\
5 & 60 & 60 & 45 & 10 \\
6 & 80 & 80 & 90 & 50 \\
\hline
\end{tabular}

Table III. Details of the MSTS and Constant score for the two surviving patients

\begin{tabular}{lll}
\hline Case No & MSTS & Constant score \\
\hline 1 & 70 & 37 \\
2 & 43 & 14 \\
\hline
\end{tabular}

six patients. The functional assessment, performed on the three surviving patients, yielded scores from 43 to 70 (maximum 100) for the MSTS and from 14 to 37 (maximum 100) for the Constant score (Table III).

\section{Discussion}

We have examined the functional outcome of patients undergoing a radical, near total, scapulectomy and glenothoracic fusion. By retaining the glenohumeral joint and stabilising it against the rib cage, a fulcrum was created about which the arm could be moved. . $^{1,9,10}$

There are three requirements for elevation at the shoulder: ${ }^{11}$ the weight of the limb acting through its centre of gravity, the abductor mechanism of the deltoid muscle innervated by the axillary nerve and forces acting against

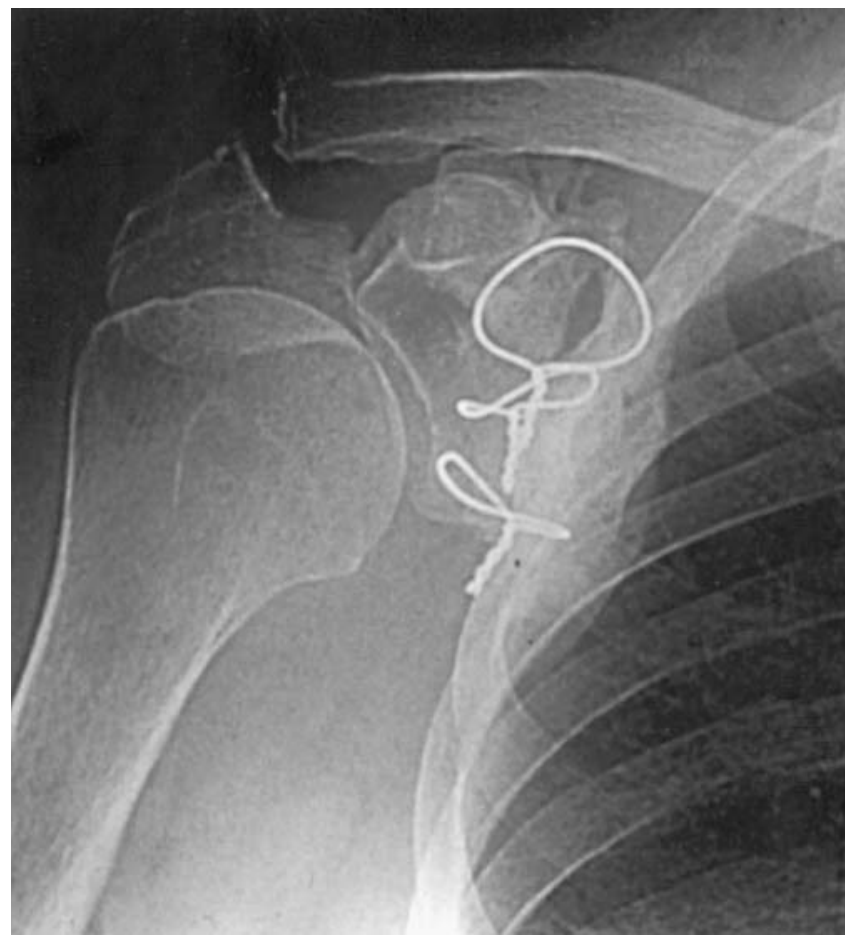

Fig. 4

Case 3. Post-operative radiograph.

and balancing this force. These structures stabilise the head of the humerus in the glenoid fossa together with the downward pull of subscapularis, infraspinatus and teres minor. These represent an efficient force couple, first described by Inman et al. ${ }^{11}$ The importance of this concept is based on

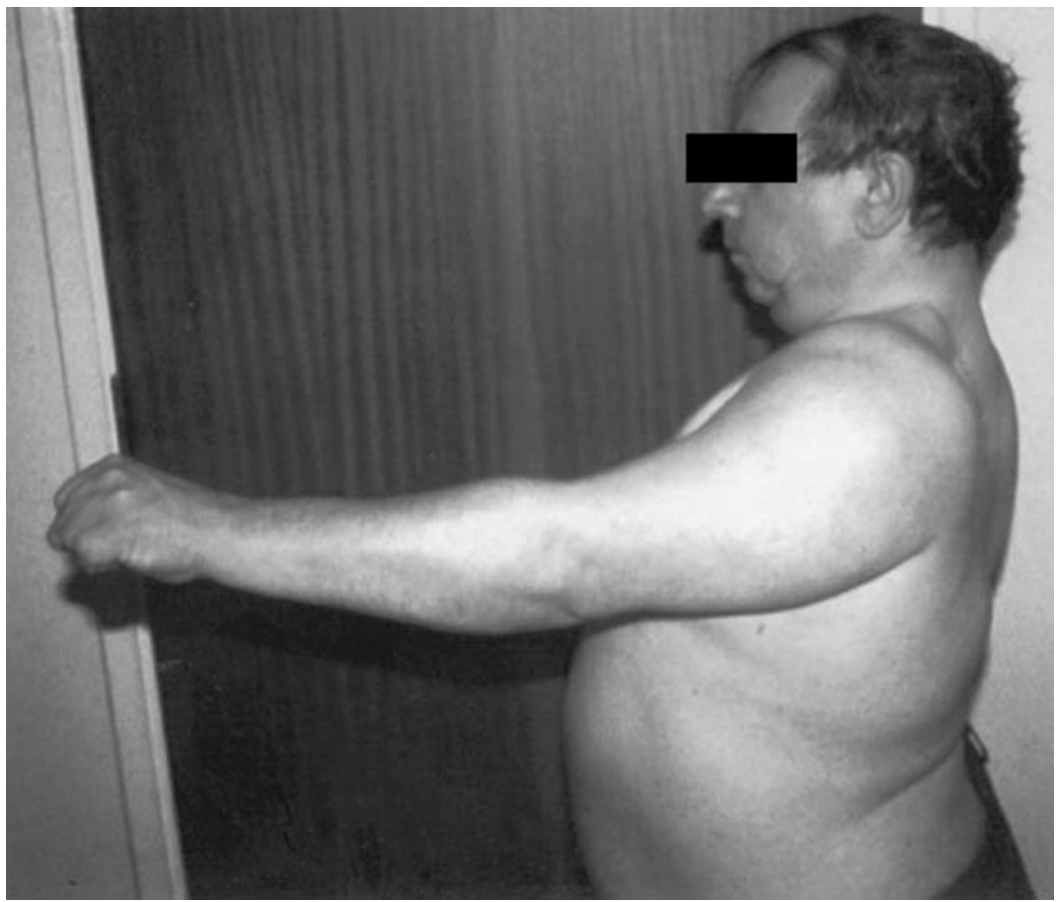

Fig. 5

Case 1. Photograph showing the range of flexion. 


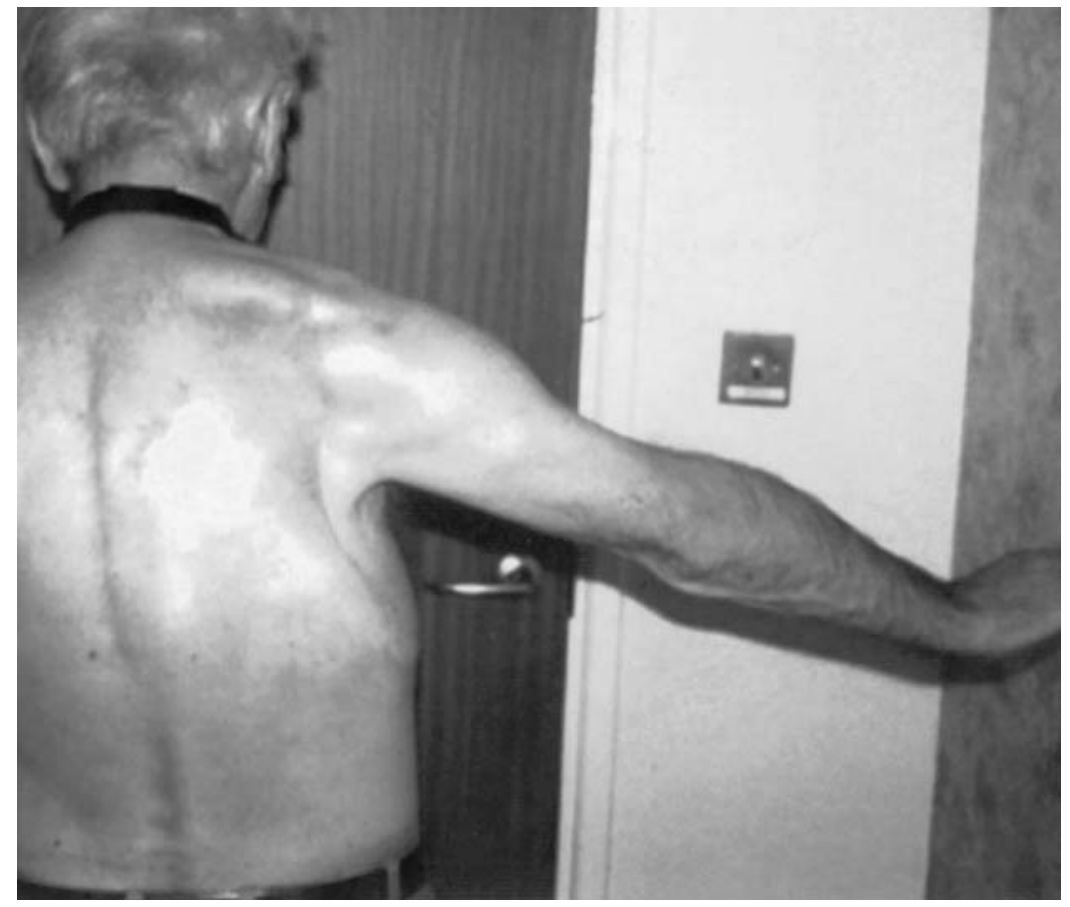

Fig. 6

Case 3. Photograph showing the range of abduction. the observation that individual muscle activity at the shoulder has little effect in producing movement unless the force couple is functioning, ${ }^{2}$ hence the value of preserving the glenoid fossa, in order to provide a reactive force to oppose that generated by the deltoid.

Under normal circumstances the glenohumeral and scapulothoracic joints work in combination to produce elevation of the arm. When the glenohumeral joint moves alone, elevation is restricted to $90^{\circ}$ in both forward flexion and abduction. ${ }^{11}$ These two movements are at least as important as internal and external rotation. ${ }^{9}$ One patient (case 1) showed the best attainable range of movement in forward flexion and abduction, according to the criteria of Inman et al. ${ }^{11}$ The other five had a mean range of forward flexion of $66.6^{\circ}$ (45 to 80 ) and of abduction of $68.3^{\circ}$ (40 to 80 ). However, since most activities of daily living are performed with the arm below $90^{\circ}$, satisfactory function was achieved (Figs 4 to 6 ). ${ }^{9}$

A further consequence of the loss of the scapulothoracic joint is loss of power. ${ }^{11}$ Analysis of the functional scores showed that all of the patients scored zero in the power-lifting category since both the MSTS and the Constant score assess power at $90^{\circ}$ of elevation in the scapular plane. This greatly reduces the Constant score because power accounts for $25 \%$ of the total. The effect is less marked in the MSTS since power accounts for only one-sixth of the total. The patients all scored well in regard to relief from pain and manual dexterity. The poorest functional outcome was seen in case 2 . This patient required a more radical excision than had previously been planned. However, surgery must give priority to the complete excision of the tumour ahead of

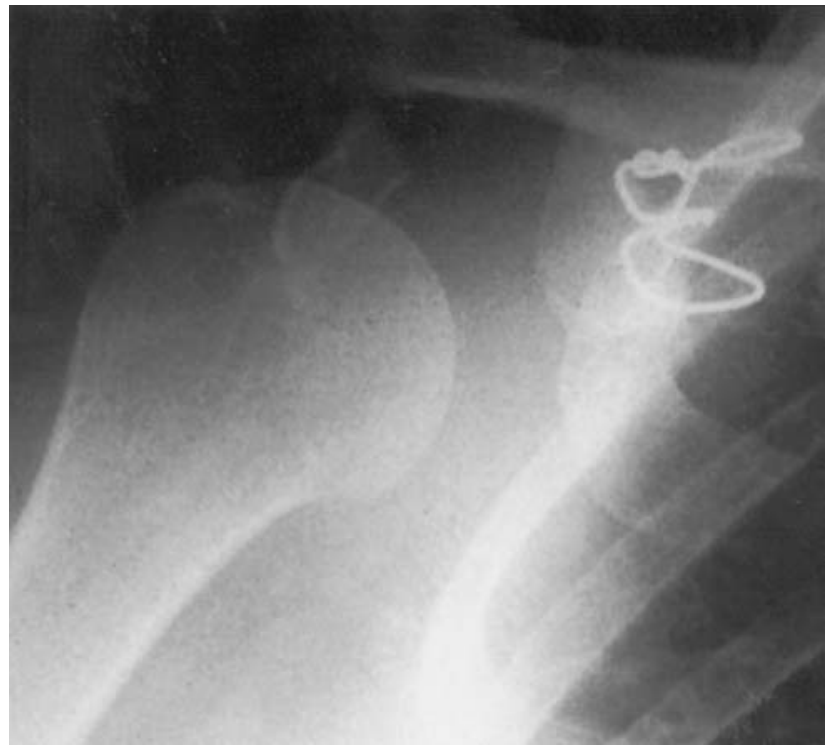

Fig. 7

Case 2. Post-operative radiograph showing a very small glenoid remnant and poor apposition of the humeral head.

prospective function. ${ }^{1,2}$ The post-operative radiograph of this patient showed a very small glenoid remnant and poor apposition of the humeral head (Fig. 7). Solid bony fusion is difficult to assess by plain radiography, but there was evidence of bone between the glenoid remnant and the thoracic cage in one patient (case 3; Fig. 8). Fusion was thought to be sound because the position of the glenoid 


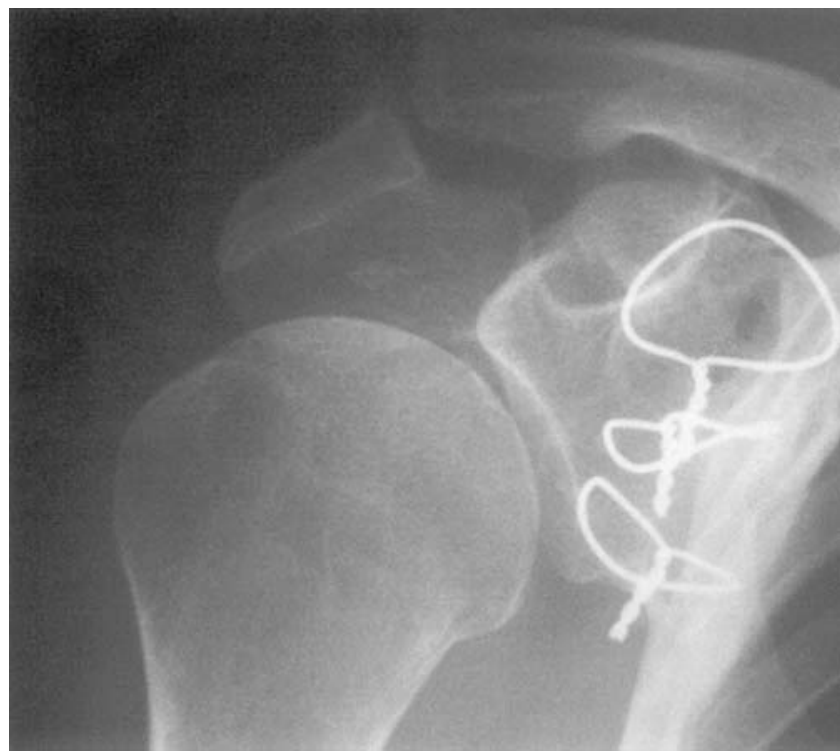

Fig. 8

Case 3. Radiograph at follow-up at two years showing bone between the glenoid element and the thoracic cage.

remnant had not altered over time; the wires were intact and the function of the limb had not deteriorated. This applied to two other patients (cases 1 and 2).

In other series, patients requiring total scapulectomy had reconstruction using the divided ends of the muscles surrounding the shoulder. Remnants of the rotator cuff, attached to the humerus, were sutured to the lateral end of the clavicle with the divided ends of trapezius and deltoid sutured together. ${ }^{1,2}$ Gibbons et $\mathrm{l}^{10}$ described an alternative method after subtotal scapulectomy. They created a muscular envelope which covered and stabilised the remaining scapula. The remnants of the rotator cuff were reattached to the residual scapula, with all neighbouring muscles closed over the defect.

Glenothoracic fusion, after a radical, near total scapulectomy, can provide an acceptable functional outcome, provided that sufficient scapular neck is retained. The three surviving patients had excellent relief from pain with manual dexterity. Although the indications are few, the operation fulfilled Linberg's condition that conservative operations must achieve at least as good an outcome as radical procedures. ${ }^{4}$

No benefits in any form have been received or will be received from a commercial party related directly or indirectly to the subject of this article.

\section{References}

1. Ward B, McGarvey C, Lotze MT. Excellent shoulder function is attainable after partial or total scapulectomy: analysis at prolonged follow-up. Arch Surg 1990:125: 537-42.

2. Syme J. Excision of the scapula. Edinburgh, Scotland: Edmondson and Douglas, 1864.

3. Papaioannou AN, Francis KC. Scapulectomy for the treatment of primary malignant tumours of the scapula. Clin Orthop 1965;41:125-32.

4. Linberg BE. Interscapulo-thoracic resection for malignant tumors of the shoulder joint region. J Bone Joint Surg 1928;10:344-9.

5. Francis KC, Worcester JN. Radical resection for tumors of the shoulder with preservation of the functional extremity. J Bone Joint Surg [Am] 1962;44-A:1423-30.

6. Badley EM, Lee J. Impairment, disability and the ICIDH Model III: underlying disease, impairment and disability. Int Rehabil Med 1987;8:174-81.

7. Enneking WF, Dunham W, Gebhardt MC, Malawar M, Pritchard DJ. A system for the functional evaluation of reconstructive procedures after surgical treatment of tumours of the musculoskeletal system. Clin Orthop 1993;286:241-6.

8. Constant CR, Murley AHG. A clinical method of functional assessment of the shoulder. Clin Orthop 1987;214:160-4.

9. Markhede G, Monastyrski J, Stener B. Scapulectomy for malignant tumour. Acta Orthop Scand 1985;56:332-6.

10. Gibbons CLMH, Bell RS, Wunder JS, et al. Function after subtotal scapulectomy of bone and soft tissue. J Bone Joint Surg [Br] 1998;80-B:38-41.

11. Inman VT, Saunders JB de CM, Abbott LC. Observations on the function of the shoulder joint. J Bone Joint Surg 1944;26:1-30. 